\title{
Differential anterograde transport of HSV type 1 viral strains in the murine optic pathway
}

\author{
Judy A Garner ${ }^{*, 1}$ and Jennifer H LaVail ${ }^{2}$ \\ ${ }^{1}$ Department of Cell and Neurobiology, University of Southern California School of Medicine, Los Angeles, California \\ 90033, USA; ${ }^{2}$ Neuroscience Program, Departments of Anatomy and Ophthalmology, University of California, San \\ Francisco, San Francisco, California 94143, USA
}

\begin{abstract}
Active anterograde transport of herpes simplex virus Type 1 (HSV-1) in neurons is often assumed based on early appearance of infection in postsynaptic target cells of a primary infected cell, and is further logically inferred by good evidence of microtubule-motor based mechanisms of retrograde transport. However, direct evidence of mechanisms of anterograde movement of newly synthesized virus in CNS neurons actually has yet to be obtained. In efforts to investigate the latter, we will be greatly aided by viral strains that exhibit differences in their ability to move in an anterograde direction. We compared the anterograde axonal transport of three HSV strains (F strain, H129, and MacIntyre B) in the murine visual system. Equivalent titers of virus were injected intraocularly in BALB/c mice. From 2-6 days after inoculation, segments of the infected optic pathway were harvested and Western blots using an anti-HSV polyclonal antibody performed. H129 traveled very rapidly towards the terminals ( 3 days post-inoculation). $F$ strain spread more slowly than $\mathrm{H} 129$, but also reached terminal regions by 4 days. MacIntyre B accumulated only in the most proximal optic nerve, and was seen only very faintly in distal optic pathway after 5 days. Coincidentally, a single viral protein appeared to be greatly reduced in expression in MacIntyre B. Our results suggest that different viral strains display variability in their capacity to spread anterogradely, and that further comparison of these strains may reveal how virus engages the host cell transport machinery.
\end{abstract}

Keywords: HSV; intracellular transport; viral transport

\section{Introduction}

Herpes simplex Type 1 (HSV) is an alphaherpes virus that preferentially infects epithelial cells of mucous membranes and peripheral processes of sensory nerves (reviewed in Enquist et al, 1998). After infection, subsequent replication and release of mature virus by epithelial cells, HSV may be taken up by the sensory nerve endings innervating that epithelium and transported back to the neuron cell bodies in sensory ganglia. Here the virus either replicates in the neuron or assumes a latent state from which it may reactivate at some later time in

\footnotetext{
${ }^{*}$ Correspondence: JA Garner, Department of Cell and Neurobiology, USC School of Medicine, 1333 San Pablo Street, Los Angeles California 90033, USA

Received 6 July 1998; revised 25 August 1998; accepted 6 October 1998
}

response to peripheral stimuli, such as UV light or stress (Roizman and Sears, 1990). After replication, and generation of mature virus, it is released from the sensory neurons to infect other nearby neuronal and supporting cell bodies (LaVail et al, 1990) and/ or is transported out the axon branches to invade the peripheral nerve endings in the skin or the central branches of the sensory cells. It may be transported from this first neuron to additional ones throughout the central nervous system (transneuronal transport) (LaVail et al, 1990), which may ultimately result in life-threatening viral encephalitis (Steiner and Kennedy, 1995).

The targeted intracellular sorting of viruses of the alphaherpes group is essential for transmission of virus from cell to cell. The mechanisms by which these neurotropic viruses accomplish this sorting to various cell surfaces domains, as well as the physical form and maturity of the virus at various 
stages of the process, are thus of considerable interest not only to those investigating viral pathogenesis in the central nervous system (CNS), but also to investigators interested in basic cellular targeting and transport of endogenous macromolecular complexes. Previous work indicates that, in vivo, HSV is transported in a retrograde direction from the cell periphery towards the cell nucleus in the form of a nucleocapsid and uses directional specific cytoplasmic motors assisted by their interactions with microtubules (Sodeik et al, 1997; Topp et al, 1994). Similarly detailed studies concerning the mechanism of anterograde transport of the virus in neurons have yet to be performed, though the physical association of anterogradely transported virus with microtubules is suggestive of the use of similar mechanisms (Penfold et al, 1994).

Different strains or clinical isolates of HSV virus appear to differ in their ability to produce neurological disease in both mice and humans (Dix et al, 1983; Richards et al, 1981) and the basis of such a difference remains largely unknown. Two particular strains of HSV type 1 (HSV) demonstrate very different patterns of transneuronal transfer in experimental encephalitic spread (Zemanick et al, 1991). MacIntyre B strain appears to undergo preferential retrograde transneuronal transport, i.e., it is transferred preferentially from infected neurons to neurons synapsing upon them, rather then infecting a postsynaptic cell upon which they synapse (Zemanick et al, 1991). H129 strain appears to undergo vigorous anterograde transneuronal transport as compared with F or MacIntyre B strains. Recent work has suggested that the preferential retrograde transneuronal spread of MacIntyre B strain may be due to defective anterograde movement of the virus in the inoculated pathway (LaVail et al, 1997).

In the current study, we have compared the anterograde movement of each of these strains of virus, as well as that of $F$ strain, a strain which is generally thought to have no preferential polarized transfer (LaVail et al, 1997). To examine more effectively the anterograde movement of newly synthesized virus, we have utilized the murine retinal ganglion cell and axon. This system allows resolution of anterograde movement of the different viral strains by virtue of axonal length within the central nervous system and the accessibility of the cell bodies for reproducible infection. It can further allow unambiguous separation of anterogradely moving virus from that moving in the retrograde direction.

It is our hypothesis that the variation in the anterograde transport observed represents variance in the ability of the different viral strains to exploit or interact with the host anterograde transport system, either at the point of initial loading into the transport system near the axon hillock or during the movement phase of transport. Thus, elucidation of potential defects in transport may provide important information about the identity of viral proteins involved in that transport process.

\section{Results}

Pathogenesis of retina after inoculation

Since retinal pathology resulting from intraocular injection of HSV might affect anterograde transport of virus in the visual pathway, we examined retinas from animals killed 3 or 4 days after inoculation. In general, the results confirmed earlier descriptions of similar experiments (Hamasaki et al, 1988; Whittum et al, 1985). HSV-positive cells were obvious in the iris and often a small patch of cells in the sclera and choroid appeared heavily infected, perhaps as a result of the needle path. The retinae were also infected, but the histopathological changes in the retina were mild. Although large segments of retina were lost in the processing, where it was present, the normal retinal architecture was preserved. We found no folds or abnormal layering. Viral antibody staining was non-uniform across the retina. There were large regions of intense immunoreactivity and other more peripheral regions where there was significantly less viral immunostaining. Within the infected areas, it appeared that the virus was capable of infecting cells in all layers (Figure 1). However, the most extensive layers of infection were the inner and ganglion cell layers. In some areas, the viral infection spread to Muller cell processes that extended into the outer plexiform and photoreceptor nuclear layers.

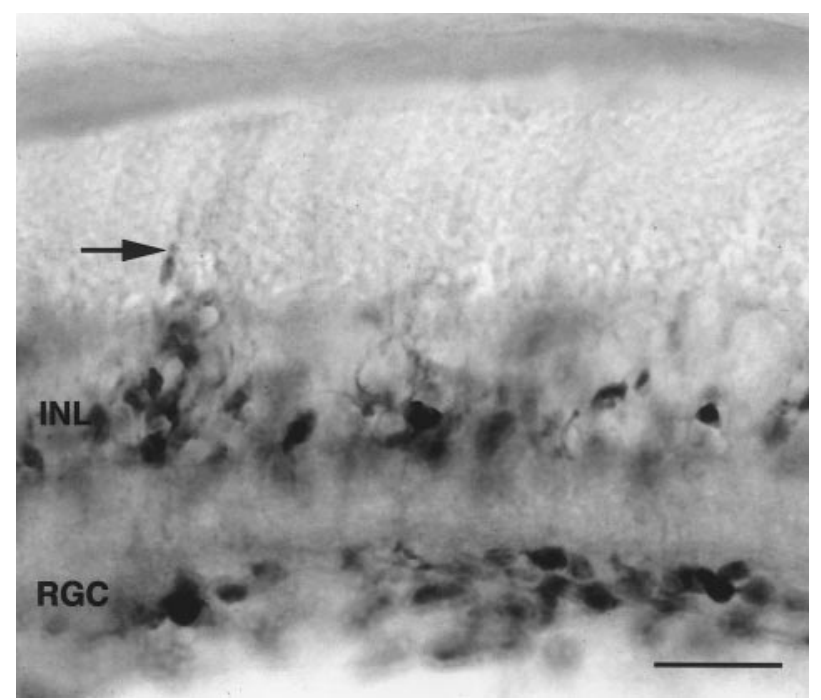

Figure 1 Immunostained retina infected with $\mathrm{F}$ strain HSV Type 1. Retinal section from mouse infected with an $\mathrm{F}$ strain of HSV and allowed to survived for 3 days. HSV infected cells in the retinal ganglion cells (rgc)and bipolar cells in the inner nuclear layer (inl) are immunopositive (dark staining). Immunostaining of possible Müller cell processes (arrow) extends into the photoreceptor cell layer. Bar $=50 \mu \mathrm{m}$. 
Anterograde movement of three different viral strains in the optic pathway

To investigate anterograde spread of newly synthesized virus in the murine optic pathway, mice that survived $3,4,5$ and 6 days after infection were used. Initial experiments showed that there was no detectable viral antigen in the optic system several millimeters away from the cell body at 2 days after injection of any of the viral strains (not shown). Production of mature infective virus in fully permissive tissue culture cells has been estimated previously to take approximately $18-20 \mathrm{~h}$ (Roizman and Sears, 1990). Potential causes of the apparent delay in appearance of $\mathrm{HSV}$ in the optic system may reflect one or more of the following: (1) intrinsic differences in viral replication in retinal ganglion cells, as opposed to replication in permissive tissue culture cells described previously, (2) differences in the rate at which virus engages anterograde transport machinery, or (3) the lack of sufficient virus to measure by Western blot in the optic system at early times.

The localization of viral antigen throughout the murine visual system at 3,4 and 5 days after intraocular injection of three different viral strains is shown in Figure 2. F strain and MacIntyre B strain, can be seen to be present in proximal optic nerve as early as 3 days post-injection. F strain distribution extends as an apparent gradient into the more distal regions of the optic nerve and chiasm, with the highest concentrations of the viral proteins seen closest to the eye. The MacIntyre B strain, however, appears to be entirely limited to the most proximal segments. The H129 strain, in contrast to both other viral strains, can be seen to extend throughout the visual system at the 3 day time point. Interestingly, H129 cannot be seen at all in the 2 day post-injection time point, suggesting that it achieves the observed distribution at a fairly rapid rate. Also, no proximal-to-distal gradient was observed, as was seen with the $\mathrm{F}$ strain virus.

By 4 days after injection, $F$ strain viral proteins were distributed fairly evenly through the optic system, and were indistinguishable from the distribution seen with the H129 virus. MacIntyre B virus at this time, though more intensely staining (suggesting increased quantity of viral antigen) was still limited in distribution to the most proximal segments of the optic nerve.

At 5 days after injection, bands from both $\mathrm{F}$ strain and H129 were intense in staining and were spread evenly throughout the optic nerve, chiasm and tract. The superior colliculus contained significant amounts of H129 viral antigen, and modest amounts of $\mathrm{F}$ strain. By this time, MacIntyre B virus also had spread distally, and the distribution appeared to be in a proximal-to-distal gradient. There was no detectable staining of the MacIntyre B virus in superior colliculus fractions.

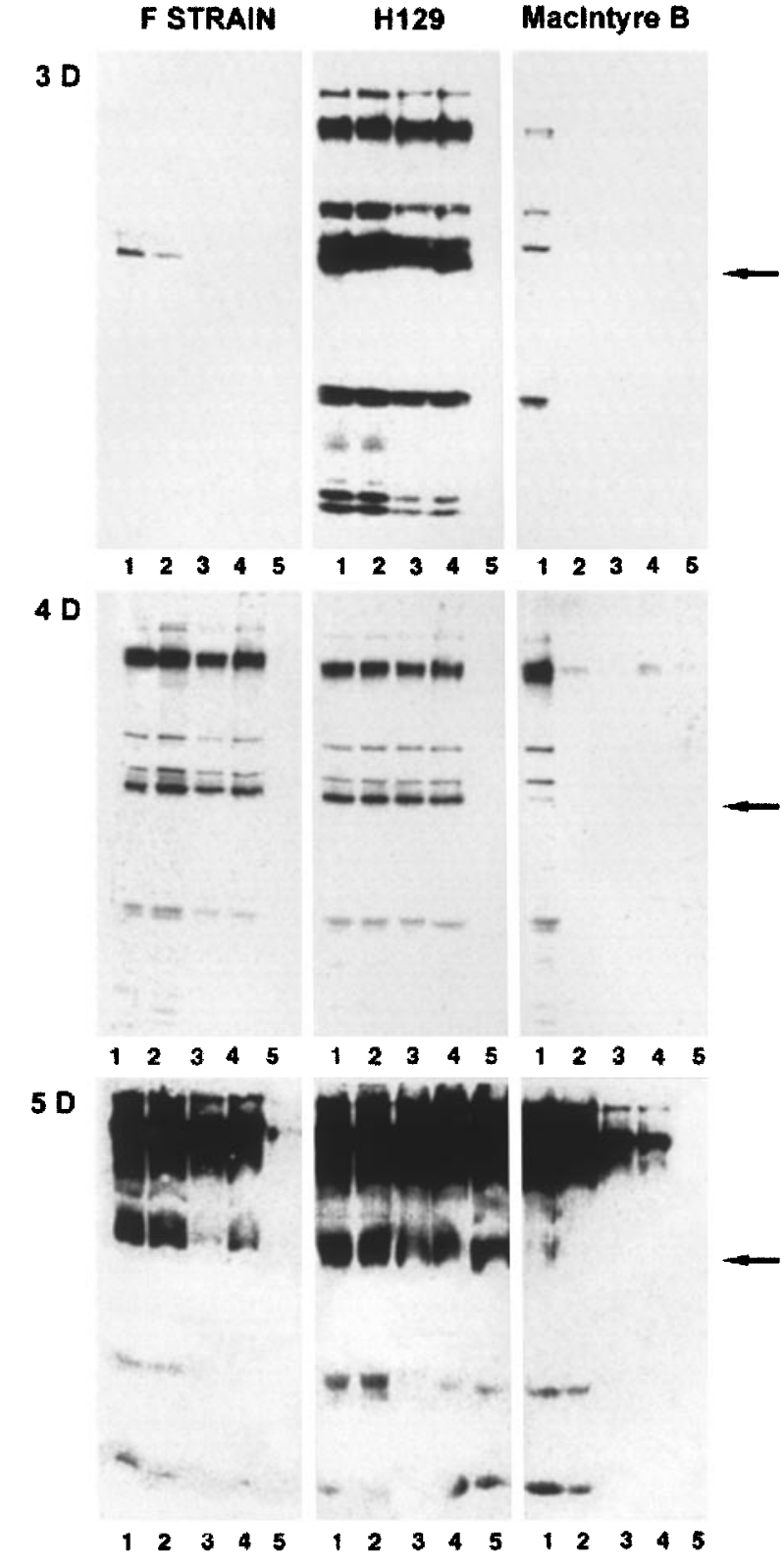

Figure 2 Western blots of different strains at different inoculation-sacrifice intervals. Western blots of the optic pathway of mice injected with equivalent titers of $\mathrm{F}, \mathrm{H} 129$, or MacIntyre B strains of Type I HSV. The animals survived 3, 4 or 5 days after intravitreal injection of virus. Lanes 1 through 5 represent the viral antigens within segments of the optic pathway as indicated in Figure 6. At 3 days, the H129 strain can be recognized throughout the visual path and the $\mathrm{F}$ and MacIntyre B strains can be seen in only the most proximal segments. By 4 days, H129 and F strain have fully penetrated the pathway, while MacIntyre B strain is still only seen in the first segment. By 5 days, F and H129 have both entered the superior colliculus, while MacIntyre $\mathrm{B}$ has reached the chiasm and proximal optic tract but has not yet fully penetrated the entire optic system. A major protein band at $\sim 100 \mathrm{kDa}$ appears to be greatly reduced in the MacIntyre $B$ viral antigen profile, as compared with F or H129 (arrow). Western blots were stained with rabbit anti-HSV (Accurate) $\operatorname{IgG}(1: 1000)$ conjugated to horseradish peroxidase and visualized using the ECL system (Amersham). 
Two features should be noted in regarding superior colliculus samples. The superior colliculus not only contains the synapses and terminal axons of the optic tract, but also large quantities of postsynaptic neuron cell bodies, glial cells, and numerous processes unrelated to the direct input from the retina. In addition, only about $50 \%$ of the RGC axons in the tract will pass the lateral geniculate nucleus to terminate in the superior colliculus. Thus any contribution of the retinal ganglion cells to the superior colliculus samples, on a weight/ volume ratio, will be significantly diluted in the colliculus sample as compared with optic nerve or tract. In addition, the superior colliculus is another 3-4 $\mathrm{mm}$ distal than the last portion of the optic tract taken for the analysis (just prior to half the terminals entering the lateral geniculate nucleus of the thalamus). Time and distance delay may be part of the answer for the delay in appearance of the virus in the colliculus, when added to the major dilution of the sample for reasons stated above.

Despite the fact that the same antibody to whole HSV was used to stain viral antigen in the case of each of these HSV strains, the profile of viral antigens stained in the MacIntyre B strain samples differed from that of $\mathrm{F}$ and H129 strains. A major protein band at approximately $100 \mathrm{kDa}$ (arrows in Figure 2) was greatly reduced in staining in the MacIntyre B samples.

\section{Immunocytochemistry of infected optic system}

The localization of viral antigen in infected optic nerve at 3 days post-inoculation is shown in Figures 3 and $4 . \mathrm{F}$ and H129 infected samples show evidence of viral antigen in threadlike axons within the optic pathway and in the nuclei and cell bodies of supporting glial cells at both 3 and 4 days (Figure $3 \mathrm{~A}$ and $\mathrm{B}$, and Figure 4). The cell bodies of the immunopositive supporting cells appear arranged in longitudinal nests of 8-10 cells in close proximity to one another. The overall level of infection of the optic pathway appeared higher in the H129 samples at 4 days, than seen in the F strain infections, consistent with the immunoblot data. Examination of $F$ strain infected optic systems at low magnification (Figure 4) shows that the infected glial cell population generally is confined to those regions containing infected axons, and that the overall level of infected axons and glia appear to be fairly evenly distributed across the entire optic nerve rather than concentrated in the central portions or at the edges of the optic nerve. MacIntyre B infected optic systems exhibited no staining of either axons or glial cell nuclei at 3 days after inoculation (Figure 3C).

\section{Replication of the three viral strains in retina}

It was important to determine if there were any detectable defect in replication rate of the viral strains in the retinal cells, as any such defect would
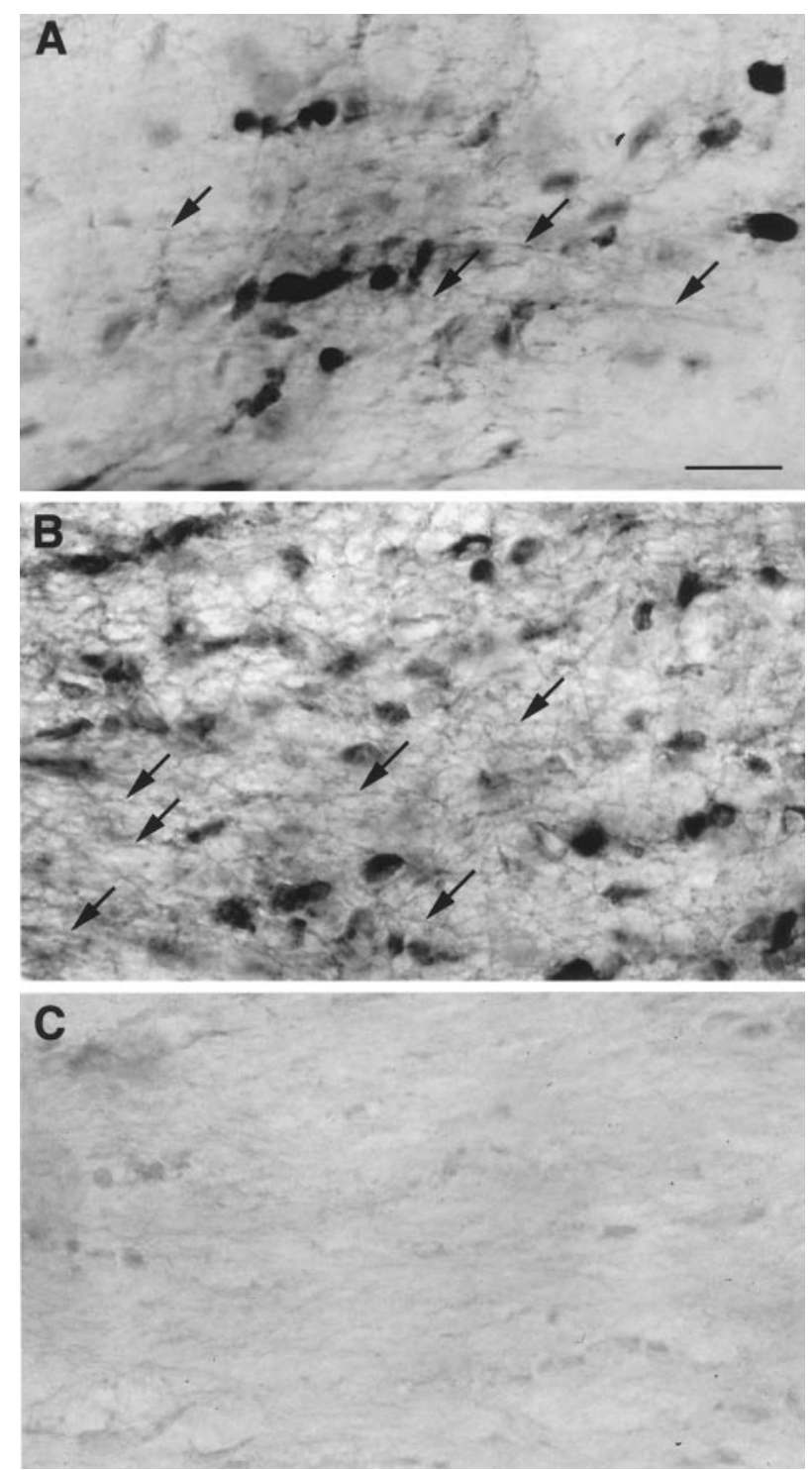

Figure 3 Immunostaining of antigen within the optic system. Immunostaining of optic nerve fibers from mice infected with $\mathrm{F}$ (A), H129 (B) and MacIntyre B (C) strains of HSV. (A) Fine caliber optic axons (arrows) course through neuropil. Immunostained oligodendroglia and astrocytes are also reactive. (B). The optic nerve of the H129 infected mice contained significantly more HSV-positive axons and glial cells. (C). The optic nerve of the MacIntyre B infected animal contained no HSV positive axons or glial cells by 3 days after infection. Bar $=30 \mu \mathrm{m}$.

obviously complicate evaluation of the new appearance of HSV antigen in the optic pathway. While titering of virus on Vero cells in vitro suggested that all three strains replicated at similar rates, it was important to examine the issue using the cell population that was infected under the proposed experimental conditions, that is, in retinal cells, as the replication rate can be cell type dependent (Javier et al, 1987). Retinae exposed to either F or MacIntyre B strains of HSV by intraocular injection of equivalent titers of the viral strains were 
harvested at 2, 3, 4 and 5 days after exposure, and viral titer within the retinal tissue determined by retitering on Vero cells. A graph showing the viral titers within the retina at each time is shown in Figure 5. Though there are slight differences in viral titer between the two viral strains, these are not statistically significant.

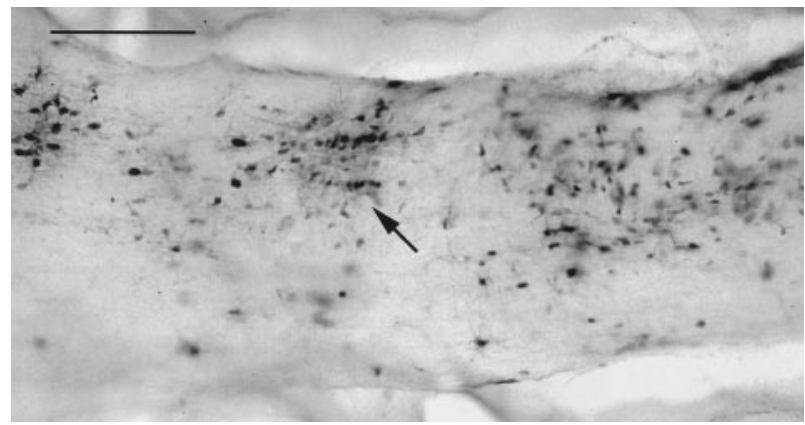

Figure 4 Low magnification of murine optic nerve infected with F strain HSV. Thick section $(50 \mu \mathrm{m})$ of murine optic nerve viewed in a low magnification light micrograph showing viral antigens present 3 days after intraocular inoculation with $\mathrm{F}$ strain virus. There is no gradient of infection from the external to internal regions, and, when viewed at higher magnification, all infected glial cells can be seen to be associated with axons containing immunoreactivity for HSV virus. Area containing a region with 'strings' of immunopositive glial cells is indicated with arrow. Retina is to the left. Bar $=250 \mu \mathrm{m}$.

\section{RETINAL TITER OF VIRAL STRAINS}

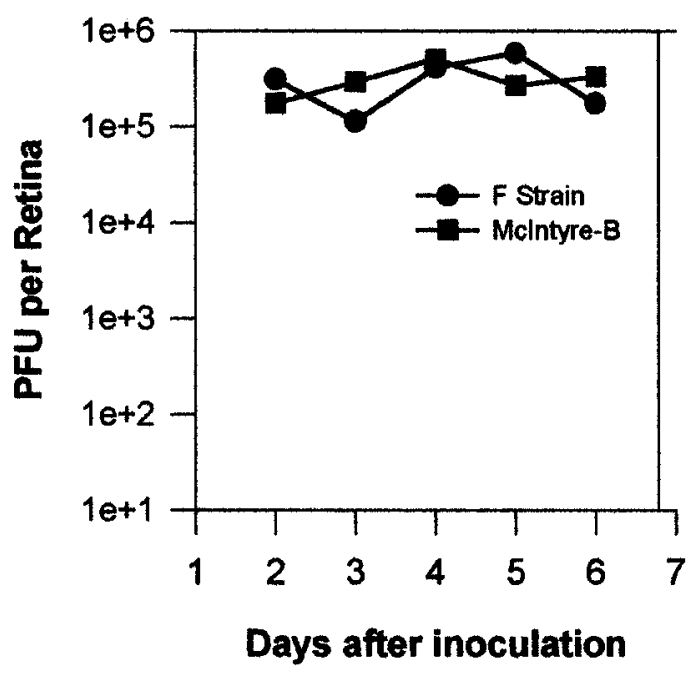

Figure 5 Graph showing viral titers in retina at different times after inoculation. Eight retinae were harvested at 2, 3, 4, 5 and 6 days after intraocular inoculation of equivalent titers of $F$ and MacIntyre B strains of HSV. Virus was collected from the retinal samples, and was retitered on Vero cells in quadruplicate. The titer of virus at each time after inoculation is shown for $\mathrm{F}(\mathbf{0})$ and MacIntyre B ( $\boldsymbol{\square}$ ). There does not appear to be significant difference in replication of either viral strain in the retina.
Western blot of retina inoculated with the three viral strains

To determine whether different viral strains are synthesized at approximately equivalent levels in the retina, and whether the viral antigen profiles were the same in the cell bodies as seen in the axons, electrophoretic profiles of extracted retinal proteins from animals infected with each strain of virus were subjected to Western blotting and compared with each other and with profiles from other parts of the optic system. At 2 days postinoculation, there were no detectable levels of HSV antigens when either $\mathrm{F}$ or MacIntrye B infected retinas were assayed, and relatively low staining for H129 (not shown). By 4 days after inoculation, there was significant viral antigen present in the retinal samples infected by each strain (Figure 6). There appeared to be slightly more viral antigen overall in the H129 samples and slightly less viral antigen overall in the MacIntyre B strain, as compared with F strain, though this was not quantifiable by the methods used. The major protein band at approximately $100 \mathrm{kDa}$ in F and H129 strain viral protein profiles was greatly reduced in the MacIntyre B

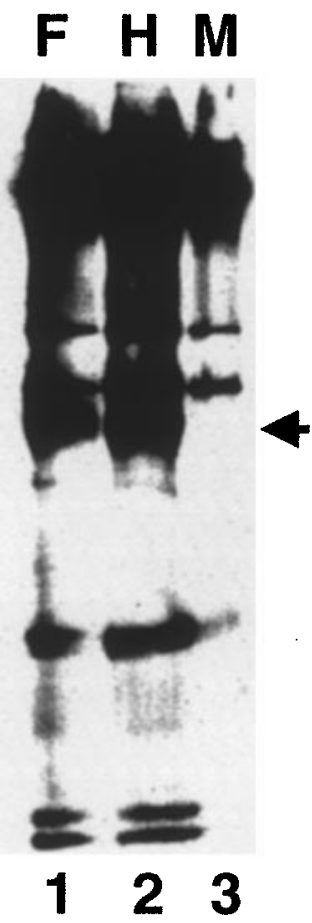

Figure 6 Viral proteins of different viral strains after replication in retina. Viral antigen in retinae from mice injected intraocularly 4 days previously with each of the viral strains was revealed by Western blot. The blot shows qualitatively that all three strains of virus appear to replicate fairly efficiently in retinae. Also, the reduced quantity of the major $\sim 100 \mathrm{kDa}$ immunopositive band in MacIntyre B was also observed in retinal samples, suggesting that the relative reduction in presence of this protein was unlikely to be due to differential anterograde movement. Western blots were stained as in Figure 2 . 
viral sample. This suggested that the reduction in the presence of this viral protein was intrinsic to the newly synthesized MacIntyre B strain, rather than due to restricted movement of this protein into the more distal optic axons.

\section{Discussion}

Anterograde movement of herpes simplex virus Early studies describing the infection of nervous tissue with herpes simplex viruses noted that the virus first infected peripheral processes of sensory neurons and was retrogradely transported to neuron cell bodies. From there, newly synthesized virus appeared to spread into the central nervous system by transfer from the one sensory neuron to its synaptic target neuron in the brain (Kristensson et al, 1974; Enquist et al, 1998). The multiple connections of the infected neurons could thus lead to encephalitis via repeated transsynaptic infection and ultimately lead to death. Thus, the routes by which this pathogenic assault of CNS neurons is achieved is of some considerable clinical concern. Moreover, the study of anterograde and retrograde movement of herpes viruses has significant implications in the potential for modified forms of this virus to serve as viral vectors for specifically targeting central nervous system neurons (Dobson et al, 1990).

Study of the phenomena of retrograde and anterograde transport in neurons led to the logical postulate that the mechanism by which the herpes virus moved to the cellular nucleus was via intracellular retrograde transport machinery, and the mechanism by which it accomplished movement to a distal synaptic site was by use of existing host anterograde transport machinery. The retrograde movement of virus has been well-investigated; it is clearly a microtubule-dependent process that occurs at speeds consistent with those seen in retrograde transport of normal cellular organelles (Kristensson et al, 1986; Sodeik et al, 1997). While anterograde movement of virus in neurons has clearly been shown (Roizman, 1991), as has anterograde transneuronal transport (Zemanick et $a l, 1991)$, the mechanisms by which it achieves that transport have not been thoroughly established.

In this study of anterograde transport of herpes virus strains, one of the questions asked was whether the viral particles of each of the strains traveling in axons of infected retinal ganglion cells were mature virus, capable of infecting other cells, or whether they started their anterograde transport as immature forms of the virus, then became increasingly 'mature' or infective over the time it took to traverse the length of the axon. The data presented in this paper confirms earlier work with HSV Type 2 (Kristensson et al, 1974), that the virus is not necessarily limited to axons within the optic nerve.
In this paper, we have shown that glial cells closely associated with infected retinal ganglion cell axons show strong evidence of infection as determined by the presence of viral antigen. The fact that glial cells at some distance from infected axons to not show evidence of infection suggests that the most efficient route of new infection of glial cells is via the infected axons rather than another source. The findings are also reminiscent of what is seen in the brainstem after infection via trigeminal nerve central processes (LaVail et al, 1990). The evidence presented in this paper, along with that we published earlier (LaVail et al, 1997), therefore suggests the viral particles are fully capable of egress from the axons and infection of cells nearby, thus they must be both 'mature' and 'infective' as they travel in these axons.

Determination of whether the optic nerve glial cells can, in turn, make mature virus capable of infecting other cells requires examination at the electron microscopic level, however. Previous work has shown that all three viral strains can infect satellite cells in trigeminal ganglion, though the MacIntyre B strain does not appear to be able to produce mature virus in those cells (Cook and Stevens, 1973; LaVail et al, 1997). At the times examined in this study, it seems unlikely that the glial cells would be providing significant levels of mature infective virus because of the time required for uptake, synthesis, and release of mature virus.

\section{Strain differences exhibiting differential preference for directional movment}

The current study has confirmed earlier findings (Zemanick et al, 1991) that the directional preference for transneuronal movement of virus between Cebus monkey cortical neurons can be considered a heritable feature of a particular strain. This earlier study, while being the first to show differential behavior of the three strains used in the present study, however, did not establish whether such differences could be due to different replication rates, as equivalent titers were not used. When similar titers were used to infect trigeminal neurons, LaVail et al noted that in addition to its noted preference for anterograde transneuronal transport, H129 displayed a predilection for anterograde intracellular transport compared to F strain. Moreover, MacIntyre B (originally noted for its apparent preference for retrograde transneuronal transport) seemed to be relatively defective at anterograde intracellular transport when compared with either of the other strains (LaVail et al, 1997). Further detailed investigation of the anterograde transport of this virus was somewhat more difficult in the trigeminal system, however, because the bundling of the central processes of labeled ophthalmic division neurons with non-labeled axons from other divisions of the trigeminal (effectively diluting the sample) made detailed 
examination of the anterograde movement of the virus difficult in this system. In addition, the pseudo-unipolar phenotype of the trigeminal neurons made it difficult to determine if viral profiles in proximity to the nucleus that we observed were moving toward or away from the nucleus during later stages of infection.

As a result of these potential difficulties, we chose to use the model of murine retinal ganglion cells to examine specifically in vivo features of anterograde movement of the virus. The system is advantageous in that the site of inoculation is wellcontained (the vitreous), the primary neuron to be examined in infected directly (unlike the trigeminal which requires pre-infection of corneal epithelial cells), the great majority of the axons in the optic pathway have a unique source, the retinal ganglion cell population, and the optic nerve and tract are easily accessible for analysis. We have shown that after virus infects the retina, all three strains replicate effectively within the retinal cell population, and that the virus moving anterogradely can be tracked in the optic system by immunoblot.

Significantly, we observed differences in the anterograde movement of the three strains of virus that were consistent with previous conclusions described for the trigeminal system (LaVail et al, 1997). Specifically, our observations were that the H129 strain appeared to travel in an anterograde direction more rapidly than the other viral strains, and the MacIntyre B strain appeared to be defective in moving in an anterograde direction. In addition, we were able to see the extent and the relative intensity of staining for viral antigen through the optic system for each strain. It must be noted, however, that the amount of antigen seen in immunoblots reflects both intra-axonal virus as well as the additional contribution of the virally infected glial cell population in the regions surrounding the infected axons. Thus, the presence of viral antigen in the optic system segments as shown in immunoblots can be regarded only as generally reflective of the degree of anterograde movement of the virus in the optic axons and cannot be seen as quantitative. It should be emphasized, however, that the absence of any viral antigen in the immunoblots was a clear indication of deficit in anterograde movement, as neither axons nor glia contained viral antigen in this circumstance (Figure 3C).

The presence of viral antigen in the most proximal segment of optic nerve in the MacIntyre B animals was a somewhat surprising observation. It would not be expected that a viral strain that is defective in anterograde transport would be able to easily traverse the considerable length of optic axons between the retinal ganglion cell body and the point of exit of those axons from the orbit. It is our hypothesis that the viral antigen routinely seen in this most proximal segment, may actually represent an accumulation of virus in the optic nerve that is not within the optic axons. This region of the optic nerve head is thought to exhibit breakdown of the blood brain barrier (Tso et al, 1975) similar to that seen at the trigeminal nerve root zone (Townsend, 1981). It is possible that the source of viral antigen in this segment may thus be virus entering into the proximal optic nerve from the vitreous or other extra-axonal sources (Kistler and LaVail, 1981). Further investigation at the electron microscopic level is required to resolve this matter.

\section{Additional strain differences in anterograde movement}

The discussion above outlines the findings in terms of the apparent limitation in anterograde movement of the MacIntyre B stain of HSV. However, there were additional observations about the variation in anterograde movement of F and H129 strains that have implications concerning their ability to engage any host or virus mechanism responsible for that anterograde movement. As discussed above, replication and de novo synthesis of virus in retinal ganglion cells followed by movement of the new virus into portions of the optic pathway where we could measure its appearance appeared to take more than 2 days for each of the viral strains. However, once that temporal threshold was past, the H129 virus appeared to rapidly traverse the entire visual pathway. If HSV is transported anterogradely by mechanisms similar to those used by the fast component of axonal transport (primarily kinesin-mediated microtubule-dependent transport) (Vallee and Bloom, 1991), we would expect it to completely traverse the extent of the murine optic pathway, which is consistent with that seen for H129 in this study, as well as rates of other HSV strains in cultured neurons (Penfold et al, 1994). F strain, alternatively, while present in the proximal optic nerve segments at 3 days post inoculation, appeared to be graded in its distribution, with less virus distally than proximally. In other words, $\mathrm{F}$ strain did not appear to be as vigorous as H129 in moving anterogradely. It is possible that the $\mathrm{F}$ strain does not engage with the host anterograde transport machinery as efficiently as does H129, or that it may interact with some competing cellular organelle that retards its anterograde spread. It is also important to note that retinal titers of the H129 virus were not performed in the retinae, in comparison with $\mathrm{F}$, leaving the possibility that the apparent rapidity with which H129 traverses the system could, in fact be due to much more efficient replication of infective virus. While this remains to be definitively examined, we think that this is unlikely because the rate of viral replication of H129 in all other cell types tested is not significantly different from F. In addition, as a very rough measure, the amount of total H129 viral antigen in 
the retina appears comparable to the amount of $\mathrm{F}$ or MacIntyre B (Figure 6).

\section{Reduction in a major viral protein in MacIntyre $B$ strain}

In addition to the significant reduction in anterograde spread of the MacIntyre B virus, we also observed a significant reduction of a major viral antigen $(\sim 100 \mathrm{kDa})$ in the same strain. At this time, we do not really know if the lack of this protein is due to some intrinsic property of the host cell or due to the intrinsic features of the virus. Samples of MacIntyre B virus grown in Vero cells also appear to have reduced immunoreactivity with this major protein (unpublished results), but at this time we do not know if this feature is generalizable to other cell types.

Known HSV proteins of approximately that molecular weight include viral envelope glycoproteins B (gB), H (gH), C (gC) and E (gE), as well as the three tegument proteins VP11/12, VP13/14, and ICPO (VP110) (Haarr and Skulstadt, 1994). gB is known to be required for attachment of mature virus to a host cell prior to uptake (Yuhasz and Stevens, 1993), and point mutations in the glycoprotein prevent uptake and replication. Preliminary experiments using monoclonal antibodies to gB (kindly provided by L Perreira) were inconclusive as to whether gB were reduced (not shown). Clearly, our strain of MacIntyre B virus is capable of replicating effectively in the retina as well as in Vero cells; if there is some mutation in $\mathrm{gB}$, it must be such that the protein's cell surface binding function is not compromised. The function of $\mathrm{gH}$ has not been investigated as fully (Gompels and Minson, 1986). Preliminary studies using monoclonal antibodies to gH (kindly provided by $\mathrm{H}$ Clarke and A Minson) have shown that glycoprotein $\mathrm{H}$ appears to be present in roughly equal quantities in all three strains of virus (not shown). The search for the identity of the reduced protein is underway. While the hypothesis that the reduction in this protein is directly or indirectly related to the ability of a particular viral strain to move in an anterograde direction is plausible, the data to not yet directly address such a claim.

\section{Summary and conclusions}

In summary, the murine optic system has revealed that three separate HSV Type 1 viral strains exhibit clear differences in their ability to move in CNS axons in the anterograde direction, with the H129 strain showing apparently enhanced ability to move towards the terminals relative to $F$ strain, and MacIntyre B showing a decreased ability to move in that direction. This is despite the observation that both the MacIntyre B and F strains demonstrate similar ability to be retrogradely transported and to replicate within retinal cells. The cause of such difference in anterograde movement is not known at this time but may relate to an intrinsic difference in the ability of each viral strain either to load onto or to engage the host transport machinery. The virus moving anterogradely also appears capable of infecting glial cells within the optic nerve, although the identification of the glial cell type infected and the ability of those glial cells to produce mature infective virus has not yet been determined definitively. In addition, if no axons were labeled, no glial cells were labeled suggesting that the glial cell infection depends upon an axonal source of virus. Last, the MacIntrye B viral antigen profile appears to be uniquely lacking in a major viral protein at $100 \mathrm{kDa}$ apparent molecular weight. The relevance of this latter observation to the observed differences in transport capacity is currently undetermined, but may well be of value to investigate.

\section{Materials and methods}

\section{Viral production, purification, and titering}

The original McIntyre B strain of HSV was a kind gift of David I Bernstein, Children's Hospital Research Foundation, Cincinnati, Ohio, USA. Viral strains were plated on Green monkey kidney (Vero) cells at high dilution. Individual plaques of virus were isolated and viral strains amplified further on Vero cells. Large quantities of virus were produced as described (Davison and Elliot, 1993). Plaque purified virus was stored frozen $\left(-80^{\circ} \mathrm{C}\right)$ in sterile Dulbecco's Minimal Essential Medium (MEM) containing $10 \%$ bovine serum albumin. After thawing, virus was titered on Vero cell cultures (Burleson et al, 1992) to determine amount of infective virus and subsequently diluted to the proper concentration in MEM. Duplicate aliquots of each dilution were plated onto monolayers of Vero cells. After a $2 \mathrm{~h}$ adsorption at $37^{\circ} \mathrm{C}$ on a rotator shaker, the dilute viral sample was removed, and the Vero cells were washed with MEM and an overlay of DME, $1 \%$ fetal calf serum, and $0.1 \%$ human gamma globulin added. After incubation for $72 \mathrm{~h}$, the cells were fixed in methanol and stained with $0.5 \%$ crystal violet. Plaques were counted and viral titers calculated.

\section{Intraocular injection}

All procedures involving animals adhered to the Society for Neuroscience Guidelines for the Use of Animals in Research and the guidelines of the USC IACUC and the UCSF Committee on Animal Research. Male BALB/c mice (6-8 weeks of age) were anesthetized by intraperitoneal injection of Avertin (Lumb, 1963), and the right cornea was treated with two drops of $1 \%$ atropine: $0.05 \%$ proparacaine $(1: 1)$ to prevent any discomfort. Solutions containing equivalent titers of previously titered plaque purified viral strains in sterile phosphate buffered saline (PBS) at concentrations of approximately $4.5 \times 10^{4}$ p.f.u. $/ \mu$ l were drawn up 
into tubing connected to a $25 \mu \mathrm{l}$ Hamilton syringe attached to a Hamilton repeating dispenser. After connecting the tubing to a 27 g needle, $1 \mu \mathrm{l}$ of virus solution was injected into the vitreal chamber of the right eye under a dissecting microscope.

After times varying from 2 to 6 days, the animals were killed by cervical dislocation and decapitation, and the optic system was quickly dissected as follows. The optic nerve, extending from the orbit to the optic chiasm was removed and cut into proximal and distal halves (each $\sim 2-3 \mathrm{~mm}$ in length, and labeled $\mathrm{ON} 1$ and ON2, respectively). The optic chiasm ( $\sim 2 \mathrm{~mm}$ in length, labeled OC) and the optic tract was removed to the point where it enters the thalamus $(\sim 4 \mathrm{~mm}$ in length, pooled and labeled OT) (see Figure 7). The superior colliculus was also collected. Each infected eye was removed, cut open, the lens and vitreous removed, and the retina was removed. Since more than $97 \%$ of albino murine retinal ganglion cell axons cross to the opposite side of the brain, uninjected eyes and appropriate unlabeled optic nerve and tract served as controls (LaVail et al, 1978).

\section{Immunocytochemistry}

Equivalent titers of H129, MacIntrye B and F strain Type $1 \mathrm{HSV}\left(4 \times 10^{4}\right.$ p.f.u./ $\left.\mu \mathrm{l}\right)$ were injected intraocularly in mice as described above, and mice allowed to survive for 3, 4 or 5 days. Animals were killed with an overdose of halothane vapor followed by intracardiac perfusion with normal saline followed by a fixative containing $4 \%$ paraformaldehyde in $0.1 \mathrm{M}$ sodium cacodylate buffer ( $\mathrm{pH} 7.2)$. The eyes and brain were removed, kept in fixative overnight. The following day they were rinsed in $10 \%$ sucrose and $5 \%$ fish gelatin (Sigma Chemical Co.) in $0.1 \mathrm{M}$ sodium phosphate buffer ( $\mathrm{pH} 7.2$ ) and embedded in $10 \%$ gelatin hardened in $2 \%$ glutaraldehyde.

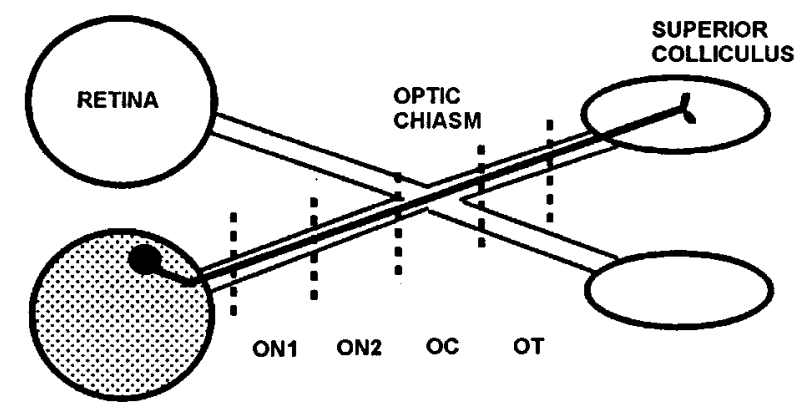

Figure 7 Diagram of the murine optic system. This is a diagram of the murine optic system showing the anatomical location of the immunocytochemistry. The great majority of axons from retinal ganglion cells in mice cross to the contralateral side at the optic chiasm. (ON1, proximal optic nerve segment; ON2, distal optic nerve segment; OC, optic chiasm; OT, optic tract). Approximately one half of the axons terminate in the LGN of the thalamus (not shown) and the other half in the superior colliculus of the midbrain.
Horizontal sections of the eye and brain were cut at $60 \mu \mathrm{m}$ thickness on a freezing microtome and reacted for the presence of HSV antigens, using standard immunocytochemical procedures (LaVail et al, 1990). Tissue sections were treated with blocking buffer (3\% normal goat serum and $0.3 \%$ Triton X-100 in phosphate buffer, $\mathrm{pH}$ 7.2) for 90 min followed by overnight incubation at $4{ }^{\circ} \mathrm{C}$ with the polyclonal rabbit anti-HSV conjugated to horseradish peroxidase (HRP) $(1: 100$, Accurate Chemical \& Scientific Corp. Westbury, NY, USA). The sections were then washed overnight in blocking buffer, incubated in HRP substrate, washed, dehydrated and coverslipped. The immunostained sections were evaluated for the presence of viral antigen. Selected $60 \mu \mathrm{m}$ thick sections containing the retina, optic nerve, chiasm, tract, lateral geniculate nuclei and superior colliculi were flat embedded in glycol-methacrylate and remounted onto microtome chucks. One to three $\mu \mathrm{m}$ thick sections were cut to facilitate identification of the cells that reacted with the viral antisera.

SDS-PAGE and immunostaining of HSV proteins For electrophoresis and immunoblotting, pooled samples from 2-4 animals were used for each gel lane. Samples were homogenized in matched glassglass homogenizers in $100 \mathrm{ul}$ of sterile DMEM on ice, solubilized in an additional $100 \mathrm{ul}$ of double strength SDS sample buffer and kept at $4^{\circ} \mathrm{C}$ overnight. Samples were electrophoresed on $10 \%$ polyacrylamide gels as described elsewhere (Garner et al, 1996). Gels were electroblotted onto nitrocellulose for 2-12 h (Harlow and Lane, 1988) at $75 \mathrm{~V} .25 \mathrm{~A}$ in $20 \%$ methanol, $25 \mathrm{mM}$ Tris, and $192 \mathrm{mM}$ glycine, at $4^{\circ} \mathrm{C}$. Blots were incubated in blotto ( $5 \%$ milk, $50 \mathrm{mM}$ Tris, $\mathrm{pH} \mathrm{7.4)} \mathrm{for} 30 \mathrm{~min}$, then in blotto containing rabbit-anti-HSV conjugated to horseradish peroxidase (Accurate Laboratories) diluted to $1: 150$ for $1 \mathrm{~h}$ at room temperature with agitation. Blots were washed four times in $0.1 \%$ Tween, $50 \mathrm{mM}$ Tris, $\mathrm{pH} 7.4$ for $15 \mathrm{~min}$ each, and subjected to a final wash in $50 \mathrm{mM}$ Tris, $\mathrm{pH} 7.4$ for $1 \mathrm{~h}$. Antibody was visualized using a ECL kit according to manufacturer's instructions (Amersham, Int.), and exposed to Hyperfilm X-ray film (Amersham, Int.) for 5-30 min. Duplicates of immunoblots were stained with amido black to reveal total protein profile.

\section{Viral replication in murine retinae}

After the optic system had been dissected free from the infected animals, the inoculated eye was removed and cut open with iridectomy scissors. The retina was dissected from the posterior portion of the eye, and all fluid exiting the eye was collected. Both were added to a known volume of DMEM containing protease inhibitors $(0.1 \mathrm{mM}$ phenylmethylsulfonyl fluoride [PMSF], Sigma Chemicals, Co; 50 U/ml Aprotinin, Sigma Chemi- 
cals, Co). The sample was gently homogenized to release viral particles. To ensure that all available virus is sampled, the remainder of the globe, the lens, and the cornea were all added to another container with known volume of DMEM containing protease inhibitors. After soaking for $2 \mathrm{~h}$, the samples were sonicated three times for $1 \mathrm{~min}$ each to release trapped viral particles. Samples were gently centrifuged at 1000 r.p.m. for $3-4 \mathrm{~min}$ to remove debris. Supernates were collected and pooled for up to two animals sharing identical experimental conditions. Aliquots of supernates were titered in quadruplicate at four serial dilutions on Vero cells as described above. Plaques were counted and number of virus particles per eye determined.

\section{References}

Burleson FG, Chambers T, Wiedbrauk DL (1992). Virology: A Laboratory Manual. Academic Press, Inc.: San Diego

Cook ML, Stevens JG (1973), Pathogenesis of herpetic neuritis and ganglionitis in mice: Evidence for intraaxonal transport of infection. Inf Immun 7: 272-288.

Davison AJ, Elliot RM (1993). Molecular Virology: a practical approach. New York: Oxford University Press, pp 315.

Dix RD, McKendall RR, Baringer JR (1983). Comparative neurovirulence of herpes simplex virus type 1 strains after peripheral or intracerebral inoculation of BALB/C mice. Inf Immun 40: 103-112.

Dobson AT, Margolis TP, Sedarati F, Stevens JG, Feldman LT (1990). A latent, nonpathogenic HSV-1 derived vector stably expresses B-galactosidase in mouse neurons. Neuron 5: 353-360.

Enquist LW, Husack PJ, Banfield BW, Smith GA (1998). Infection and spread of Alphaherpesviruses in the Nervous System. Advances in Virus Research, in press.

Garner JA, Linse KD, Polk RK (1996). Type I Brain hexokinase, axonal transport and membrane associations within central nervous system presynaptic terminals. J Neurochem 67: 845-856.

Gompels U, Minson A (1986). The properties and sequence of glycoprotein $\mathrm{H}$ of herpes simplex type 1. Virol 153: $230-247$.

Haarr L, Skulstadt S (1994). The herpes simplex virus type 1 protein structure and molecular functions. APMIS 102: $321-346$.

Hamasaki DI, Rix RD, Atherton SS (1988). Bilateral alterations of the ERG and retinal histology following unilateral HSV-1 inoculation. Invest Ophthalmol Vis Sci 29: $1242-1254$.

Harlow E, Lane D (1988). Antibodies: a laboratory manual. Cold Spring Harbor Laboratory Press: Cold Spring Harbor, NY.

Javier RT, Thompson RL, Stevens JG (1987). Genetic and biological analyses of a herpes simplex virus intertypic recombinant reduced specifically for neurovirulence. J Virol 61: 1978-1984.

\section{Acknowledgements}

The authors would like to acknowledge Ms Nerissa Mendoza for her excellent technical assistance; and Drs Marian Chin and Kimberly Topp for helpful discussion of the results and suggestions for experiments. We would also like to thank Drs L Perreira, H Browne and A Minson for their generous gift of antibodies to viral glycoproteins, and Dr David Bernstein for his gift of MacIntyre strain HSV virus. This work was supported by a grant from That Man May See, Inc., to JHL, NIH grant EY08773 to JHL, and the LK Whittier Foundation award to the Cell and Neurobiology Department, USC School of Medicine.

Kistler HB, LaVail JH (1981). Penetration of horseradish peroxidase into the optic nerve after vitreal or vascular injections in the developing chick. Invest Ophthalmol Vis Sci 20: 705-716.

Kristensson K, Ghetti B, Wisniewski HM (1974). Study on the propagation of Herpes Simplex Virus (Type 2) into the brain after intraocular injection. Br Res 69: $189-201$

Kristensson K, Lycke E, Roytta M, Svennerholm B, Vahine A (1986). Neuritic transport of herpes simplex virus in rat sensory neurons in vitro. Effects of substances interacting with microtubular function and axonal flow [Nocodazole, taxol, and erythro-9-3(2-hydroxynonyl)adenine]. J Gen Virol 67: 20232028.

LaVail JH, Nixon RA, Sidman RS (1978). Genetic control of retinal ganglion cell projection. J Comp Neurol 182: $399-422$.

LaVail JH, Topp KS, Giblin PA, Garner JA (1997). Factors that contribute to the efficiency of transneuronal spread of herpes simplex virus. J Neurosci Res 49: $485-496$.

LaVail JH, Zhan J, Margolis TP (1990). HSV (Type 1) infection of the trigeminal complex. Br Res 514: 181188.

Lumb WW (1963). Small Animal Anesthesia. Lea and Feibiger: Philadelphia, PA.

Penfold MET, Armati P, Cunningham AL (1994). Axonal transport of herpes simplex virions to epidermal cells: Evidence for a specialized mode of virus transport and assembly. Proc Natl Acad Sci USA 91: 65296533.

Richards JT, Kern ER, Overall JC, Glasgow LA (1981). Differences in neurovirulence among isolates of Herpes simplex virus types 1 and 2 in mice using four routes of infection. J Infect Dis 144: 464-471.

Roizman B (1991). Herpesviridae: a brief introduction. In: Fundamental Virology, 2nd ed. Fields BN, Knipe DM (eds). Raven Press Ltd: New York, pp 841-847.

Roizman B, Sears AE (1990). Herpes simplex viruses and their replication. In: Virology, 2nd edn. Fields BN, Knipe DM (eds). Raven Press: New York, pp 17951841. 
Sodeik B, Ebersold MW, Helenius A (1997). Microtubulemediated transport of incoming herpes simplex virus 1 capsids to the nucleus. $J$ Cell Biol 136: $1007-1021$.

Steiner I, Kennedy PG (1995). Herpes simplex virus latent infection in the nervous system. J Neurovirol 1: $19-29$.

Topp KS, Meade LB, LaVail JH (1994). Microtubule polarity in the peripheral processes of trigeminal ganglion cells: Relevance for the retrograde transport of herpes simplex virus. J Neurosci 14: 318-325.

Townsend JJ (1981). The relationship of astrocytes and macrophages to CNS demylination after experimental herpes simplex virus infection. J Neuropath Exp Neurol 40: $369-379$.

Tso MOM, Shih C-Y, McLean IW (1975). Is there a blood-brain barrier at the optic nerve head? Arch Ophthalmol 93: 815-825.
Vallee RB, Bloom GS (1991). Mechanisms of fast and slow axonal transport. Ann Rev Neurosci 14: 59-92.

Whittum JA, McCulley JP, Niederkorn JY, Streilein JW (1985). Unilateral inoculation of herpes virus into the anterior chamber produces a bilateral uveitis with a pathogenesis potentially related to anterior chamberassociated immune deviation (ACAID) In: Advances in Immunology and Immumopathology of the Eye. O'Connor GR, Chandler JW (eds). Masson Publishing, USA, Inc.: New York, pp 215-221.

Yuhasz SA, Stevens JG (1993). Glycoprotein B is a specific determinant of herpes simplex virus type 1 neuroinvasiveness. J Virol 67: 5948-5954.

Zemanick MC, Strick PL, Dix RD (1991). Direction of transneuronal transport of herpes simplex virus 1 in the primate motor system is strain-dependent. Proc Natl Acad Sci USA 88: 8048-8051. 